\title{
Organisational Learning Through the Evaluation of Information System Investments
}

\author{
M. P. Kennerley and A. D. Neely \\ Centre for Business Performance \\ Judge Institute of Management Studies, University of \\ Cambridge, Trumpington Street, Cambridge, CB2 1AG, UK. \\ Tel. +441223339597_Fax+441223339701 \\ Emailmpk21@eng.cam.ac.uk
}

\begin{abstract}
The difficulties of evaluating the impact of information systems on business performance are experienced by practitioners and academics alike. This paper presents a robust quasi-experimental methodology for evaluating the impact of information system investment on business performance. The methodology uses a range of data collection approaches to provide an in-depth insight into the business value of information systems. The paper goes on to discuss the way in which such evaluation is used to facilitate single and double loop learning.
\end{abstract}

Keywords

Information system evaluation, organisational learning, performance measurement. 


\section{INTRODUCTION}

In today's competitive market place organisations are forced to seek continually new and improved ways of operating. Concepts such as the extended enterprise, agile manufacturing, business process re-engineering, globalisation and knowledge management have all been suggested as methods of enhancing business performance. In recent years numerous organisations have made substantial investments in information systems, both because they are a key enabling technology in the improvement programmes identified above, and because they deliver substantial efficiency and effectiveness benefits in their own right. As with all substantial investments, however, the returns from investments in information systems should be evaluated. Not least because this enables the organisation to learn from past experiences and hence better manage future investments. The aim of this paper is to explore how such investments can be evaluated in a way which ensures the necessary organisational learning takes place. More specifically this paper seeks to address two substantive questions:

- How can the business impact of information systems (IS) investments be evaluated?

- How can the evaluation be carried out in a way which ensures the necessary organisational learning occurs?

The first of these questions is discussed in a rich stream of literature centred around the evaluation of information systems (Willcocks, 1994; 1996; Farbey et al., 1995). Even a cursory review of this literature makes it clear that the problems of evaluating information system investments are a major concern for both management and researchers, and much of the evaluation that is carried out is based on simple financial criteria such as return on investment and cost benefit analysis (Galliers, 1995). This focus appears to be too narrow, when one considers that businesses today are increasingly emphasising the strategic implications of their information systems (Farbey et al., 1995). Centralised databases, management information systems and intranets are all said to deliver strategic, as well as operational benefits (Willcocks, 1996). BT, for example, publishes its Quality of Service report on the internet ${ }^{1}$. One of the reasons for this is that BT wishes to inform, and influence, customer perceptions of the service BT delivers. To assess the effectiveness of this strategic application of an information system, BT has to monitor customer perceptions. The same argument can be applied to management information systems. If they are effective, the service delivered to customers should be enhanced. Hence to assess their effectiveness, customer

1 See http://www.bt.com/quality_of_service/index.htm 
perceptions of service levels have to be monitored.

Such arguments are widely accepted in the strategic management and business performance literatures (Neely et al, 1995). To date, however, there is limited evidence that they have been adequately explored in the context of information systems evaluation. Following a review of both the information systems evaluation and business performance literatures this paper presents an evaluation framework that addresses this shortcoming by building on the work of both DeLone and McLean (1992) and Kaplan and Norton (1996).

Once the evaluation framework has been presented the paper moves on to address the second question raised above - i.e. "how can the evaluation be carried out in a way which ensures the necessary organisational learning occurs"? The paper will explain this methodology in more detail, and use practical examples to demonstrate how the methodology enables the business concerned to:

1. Evaluate the business impact of the information system.

2. Single loop learn (Argyris and Schon, 1996) by identifying and rectifying problems with the information system as it stands.

3. Double loop learn (Argyris and Schon, 1996) by challenging the assumptions underpinning the implementation process thereby improving it for further applications.

\section{THE EVALUATION METHODOLOGY}

The question of how to evaluate the impact of information systems is widely discussed in the information systems literature. Many authors suggest that investments in information systems should be evaluated, however there is a lack of consensus on how this should be carried out given the difficulties of identifying the impact on business performance. A common theme underlying these calls is the widespread recognition that information systems frequently fail to deliver the predicted productivity and efficiency benefits (Willcocks and Lester, 1996). It is clear from the literature that information systems are increasingly being implemented to support strategic, as well as operational organisational objectives. Software packages such as SAP, for example, are designed not only to smooth flows of material, information and money, but also to provide senior management with the data they require to make strategic decisions about supplier partnerships, the range of products their organisation offers, the capacity it has, etc. Information systems are also seen as having a major role to play in improving customer service. The extensive use of EDI (electronic data interchange) in the automotive industry, for example, has not only taken cost out of the supply chain, but also enabled suppliers to understand better and respond more rapidly to the needs of 
their customers. Indeed it appears that growing numbers of organisations believe that information systems are one of the ways of achieving a sustainable competitive advantage (Rotemberg and Saloner, 1991).

The authors are currently participating in a European project funded under the ESPRIT programme which involves a major packaging company implementing a transnational information system. In the course of this project the authors have had an opportunity to apply the evaluation framework outlined in this paper using a quasi-experimental design, involving four different European sites (Cook and Campbell, 1979). Three main data collection strategies have been adopted:

\section{Collection of business performance data.}

The existence of four comparable business units in UK, Spain, France and Germany provide an opportunity to collect comparable business performance data. As the information system is not being implemented concurrently in all of the business units, the different sites act as control groups for each other at different stages in the implementation process. This facilitates the process of identifying which changes in business performance are a result of the new information system and which are caused by general changes in business operating conditions.

\section{Survey of system users.}

The business performance data collected in stage 1 allow hypotheses about the impact of the new information system to be developed. Further evidence to support or refute these hypotheses is sought through surveys which ask systems users to explain their perceptions of the impact of the information system.

\section{Interviews with key personnel.}

Follow-up interviews are conducted with key personnel to further enrich the data collection process. These interviews enable differences in perception that are highlighted during the survey to be explored and an in-depth understanding of the impact of the information system on business performance to be gained.

The methodology is designed to place greater emphasis on the evaluation of the impact of the information system on strategic and operational business performance than usually tends to be the case. A balanced set of measures of business performance has been developed using the most prevalent of a number of performance measurement frameworks, the Balanced Scorecard (Kaplan and Norton, 1996). This framework balances financial performance with non-financial elements of performance relating to the customer, internal operations and learning. Furthermore, in line with critics of the Balanced Scorecard, the performance of suppliers is also considered. 


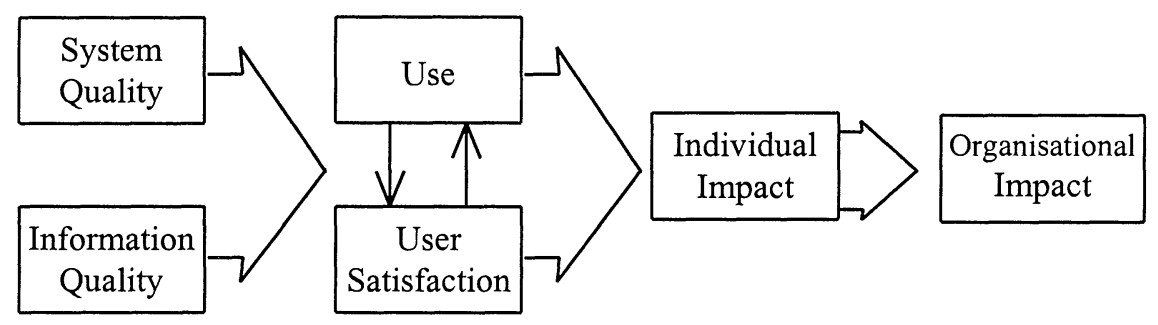

Figure 1 Information System Success Model (DeLone and McLean, 1992)

The information system success model (DeLone and McLean, 1992), shown in Figure 1, provides an appropriate framework to link lower level measures of information system performance to the organisational level measures contained within the balanced scorecard. The framework shows the complexity and multidimensional nature of the construct of information system business value. The model, with consideration of its critics, has been used as a means of structuring both the survey and interview stages of the data collection. Rather than being a constraint the model is used as a framework populated with detailed measures and questions designed to investigate each of the elements of the model in considerable depth.

\section{PRELIMINARY EVALUATION FINDINGS}

Preliminary findings suggest that there have been performance improvements at an operational level, for example improvements in data accuracy, decision making speed and effectiveness and the ability to analyse data. Furthermore there is already evidence of more tangible performance improvement at a group level. The transnational nature of the system facilitates the optimisation of performance at this level. Cost reductions have been achieved through the consolidation of stocks of machine parts that had been held simultaneously at different business units and the time to consolidate month end financial data from different business units has also been reduced.

However at a business unit level there has been no observable impact on high level business performance in the short term. This is to be expected as there is expected to be a time lag between system implementation and performance impact. The hypothesis is that the lower level operational improvements will have positive organisational impact of future performance as decision making and control of operations are improved. The need for greater training and support and dissatisfaction with the format and complexity of the system also point to a time lag before performance impact as system users adapt to using the new system (Kennerley and Neely, 1998). 


\section{SINGLE AND DOUBLE LOOP LEARNING IN ACTION}

The findings of the evaluation show that the adoption and development of information systems continue beyond its implementation. As a result it is important that organisations learn about their operation in order that they improve. The evaluation reported in this paper shows that single and double loop learning have a significant contribution to make with regard to information systems.

\subsection{Single Loop Learning}

The research has found evidence that single loop learning has a significant influence on the adoption, use and impact of information systems whilst contributing to improved effectiveness. A recurring observation confirms the correlation between information and system quality and system use as illustrated in DeLone and McLean's Information System Success Model (DeLone and McLean, 1992). However it is suggested that this is a two-way relationship. In addition to poor system quality reducing confidence in the system and hence its use, it is also clear that low usage levels of the system, or a specific part of it, reduce the identification and eradication of errors both in data and system design. This proves to be a vicious circle as the system fails to improve or more closely satisfy user requirements it discourages its use and subsequent improvement and development. The research indicates that this vicious circle has been the cause of resistance to use and development of the system.

It is clear from these preliminary findings that learning has a significant role to play in the development, adoption and use of information systems. It is important that inaccurate data and gaps in requirements to be identified and rectified quickly so that the system is fully utilised and duplication of work or use of informal systems can be eliminated.

The process of formally evaluating the information system has a significant role to play in this learning process. In particular the comprehensive nature of the evaluation approach reported ensures that lessons are learnt from all areas of the organisation, covering all of the affected processes and performance factors. In order for the evaluation to add value the lessons learnt widespread feedback must be undertaken. This should not only include users and those able to make operational improvements, but also as a means of illustrating the benefits the system can bring to those who are sceptical about the system.

\subsection{Double Loop Learning}

Review of the implementation process is of particular importance given the nature of the project being evaluated. In this case the implementation process is not a one off project as is often the case, the standard information system is to be rolled out as part of a broader pan European project. Review and evaluation of the implementation process, especially following the initial implementations, is 
important to ensure that each implementation is more effective than the last.

Table 1 shows how lessons from the first implementation in the UK improve the second implementation in Spain. Learning from the UK implementation led to greater focus on the involvement of key system users and strict procedures for dealing with changes to the core system. The data also shows that issues regarding availability of support and education and training were also addressed for the second implementation. These improvements relate to issues that are thought to contribute to the time lag between implementation and performance impact, clearly implying that learning improves the effectiveness of implementation which in turn improves adoption and reduces the time lag before performance improvement is realised. This hypothesis provides an significant area for further investigation as the evaluation continues.

Table 1 Implementation Satisfaction in the UK and Spain

\begin{tabular}{lccc}
\hline & $U K$ & Spain & 7 point Likert Scale \\
\hline Overall Satisfaction & 5.49 & 4.48 & \\
& & & 1 = Very satisfied \\
Education and training & 6.17 & 4.6 & \\
Availability of supplier support & 6.1 & 5 & $7=$ Very dissatisfied \\
Availability of internal support & 5.45 & 3.33 & \\
Timeliness & 5.17 & 4.83 & \\
Key user consultation & 5.1 & 4.25 & \\
Speed & 4.92 & 4.33 & \\
\hline
\end{tabular}

\section{CONCLUSIONS}

This paper presents a robust methodology for evaluating information systems. The quantitative and qualitative data being collected provides an in-depth insight into the impact of information systems on business performance.

The preliminary findings show the contribution that learning, both single and double loop, can make to the adoption, use and impact of information systems. Single loop learning contributes to improved operational performance of systems once implemented whilst double loop learning ensures that lessons from previous implementation projects are incorporated into the planning of future projects.

Whilst such learning can take place informally, the use of formal structured evaluation techniques ensures that a comprehensive review is undertaken and that lessons are learnt regarding all affected areas of performance and processes. 


\section{ACKNOWLEDGEMENT}

The authors are grateful to the European Commission for the award of the grant to support this study which is funded under the Technologies for Business Processes domain of the ESPRIT programme.

\section{REFERENCES}

Argyris, C. and Schon, D.A. (1996) Organisational Learning II: Theory, Method, and Practice, Addison-Wesley Publishing, Reading, MA.

Cook, T.D. and Campbell, D.T. (1979) Quasi-Experimentation: Design and Analysis Issues for Field Settings, Houghton Mifflin, Boston, MA.

DeLone, W. H. and McLean (1992) Information System Success: The Quest for the Dependent Variable, Information Systems Research, 3, 1, 60-95.

Farbey, B., Targett, D. and Land, F. (eds) (1995) Hard Money - Soft Outcomes: Evaluating and Managing IT Investment, Alfred Waller, Henley on Thames.

Galliers, R.D. (1995) Rethinking IT evaluations in the context of business systems strategy, in Hard Money - Soft Outcomes: Evaluating and Managing IT Investment (ed. Farbey, B., Targett, D. and Land, F.), Alfred Waller, Henley on Thames, 5-16.

Kaplan, R.S. and Norton, D.P. (1996) The Balanced Scorecard - Translating Strategy into Action, Harvard Business School Press, Boston, MA.

Kennerley M. and Neely A., (1998) Evaluating the Impact of Information Systems on Business Performance, Proceedings of the Fifth European Operations Management Association Conference, 14-17 June, Dublin.

Neely, A.D., Gregory, M. and Platts, K. (1995) Performance Measurement System Design: A Literature Review and Research Agenda, International Journal of Operations and Production Management, 15, 4, 80-116.

Willcocks, L. (ed.) (1994) Information Management: The Evaluation of Information Systems Investments, Chapman and Hall, London.

Willcocks, L. (ed.) (1996) Investing in Information Systems: Evaluation and Management, Chapman and Hall, London.

\section{BIOGRAPHY}

Mike Kennerley is and industrial research fellow in the Centre for Business Performance at the University of Cambridge. His research interests include business performance measurement and information system evaluation.

Andy Neely is a fellow of Churchill College and a lecturer in the Judge Institute of Management Studies and the Institute of Manufacturing at the University of Cambridge. His research interests include business performance measurement and operations strategy. 